\section{Global control}

\section{Integrated Pest Management \\ Reviews}

Editor David Dent

Chapman and Hall. 4/yr. Print and online:

Europe $£ 235$, elsewhere $\$ 390$ (institutional);

Europe $\mathfrak{E 6 5}$, elsewhere $\$ 110$ (personal). Print

only: Europe $£ 195$, elsewhere $\$ 325$

(institutional)

\section{Lawrence M. Hanks}

After the Second World War, it seemed that victory over insects was at hand; new 'miracle' insecticides, including DDT, rendered crops invulnerable and were finally eliminating ancient insect-borne diseases. But, all too soon, insect strains highly resistant to these insecticides were popping up all over the world, and our chemical 'magic bullets' were becoming blanks. Entomologists were forced to give up the dream of eradicating insects, and to start trying to manage their populations by integrating a variety of pestcontrol measures.

This Swiss army knife approach, integrated pest management, demands a sophisticated understanding of the behaviour, ecology and evolution of pests. For example, effective suppression of pest populations might be achieved through some combination of plant resistance, predation, parasitism, disease and judicious application of insecticides. For any particular pest species, studies evaluating the efficacy of various control methods, applied singly or in concert, are presented in articles scattered across entomological journals.

Integrated Pest Management Reviews fills a niche by providing satisfyingly complete reviews on all aspects of pest management. And the journal does not limit itself in types of pests (insects, nematodes, pathogens, weed plants, mammals, birds) or ecosystems (forest, agriculture, horticulture, veterinary, medical, urban). Articles in the first few volumes have been truly international; many articles review research on pest species of widespread importance or aspects of pest management for some of the world's most important crops (maize, cotton, soya bean, potato). This global approach will be greatly appreciated by readers with a general interest in methods effective in managing pests.

Also included are reviews of products and books related to pest management. On average, articles run to 15 pages with three to five articles per issue. The layout is of high quality with clear text and figures, and dates of the cited literature indicate that publication is prompt. The journal is available in print and on the Internet.

Lawrence M. Hanks is in the Department of Entomology, University of Illinois, 320 Morrill Hall, 505 South Goodwin Avenue, Urbana, Illinois 61801, USA.

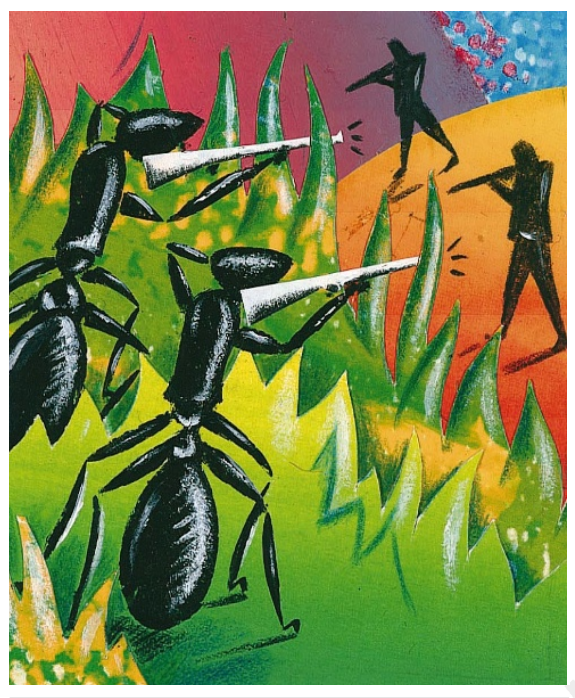

\section{Find that molecule}

Journal of Biomolecular Screening: The Official Journal of the Society for Biomolecular Screening

Editor Mark Crawford

Liebert. 4/yr. USA \$185, elsewhere \$236 (institutional); USA \$127, elsewhere \$146 (personal)

\section{NealS. Burres}

In response to mounting competitive pressure, the pharmaceutical, agricultural and biotechnology industries have made changes in their discovery programmes to identify lead candidate molecules more quickly and to reduce development failures and costs. The growth in the number and variety of assays has placed renewed emphasis on highthroughput screening as a source of quality drug candidates. Screening countless natural product extracts and chemical libraries has long been a workhorse of drug discovery, so recent advances in chemistry, biology, automation and information management have created a need for a new forum for the exchange of ideas.

The Society of Biomolecular Screening meets this multidisciplinary need. As its house organ, Journal of Biomolecular Screening includes society updates and provides a place for working groups to promote standards.

Take microtitre trays for automated handling. The typical biochemist may think that all trays are interchangeable and perhaps somewhat boring, but the automation engineer knows all too well that small variations in the dimensions of commercial microtitre plates represent an immense range for a robotic gripper system.

Also published in each issue are three to five original articles covering a wide range of topics of interest to the screening industry. Well written and attractively illustrated, they describe assay technology, combinatorial chemistry techniques and automation. A stimulating feature is a 'point-counterpoint' debate that aims to reach a compromise between pragmatic demands and ideal goals in screening. I found the technical reports describing product applications informative, considering the importance of instrumentation in this field.

The journal should provide a useful forum for discussion of assay technologies, automation strategies and their integration into screening programmes.

Neal S. Burres is at Aurora Biosciences Corporation, 11149 N. Torrey Pines Road, La Jolla, California 92037, USA

\section{A suitable treatment}

\section{Antiviral Therapy}

Editors-in-chief Joep M. A. Lange and

Douglas D. Richman

MediTech Media. 4/yr. £200, \$300

(institutional); $£ 50$, $\$ 75$ (personal)

\section{Robin A. Weiss}

All of us, bar the shareholders in pharmaceutical companies, would agree that prevention is better than cure. But despite the eradication of smallpox and the success of vaccines against yellow fever, polio and the hepatitis- $B$ virus, there are several viruses that continue to lay us low with the common cold, knock us out in one blow with influenza or ebola, or kill us more slowly with AIDS. There is therefore a burgeoning interest in antiviral therapy, the eponymous field of this journal, and the journal succeeds in satisfying this interest.

Since its launch in January 1996, Antiviral Therapy has published high-quality original articles and several thought-provoking editorials. As the editors lament in their first anniversary issue, the quarterly journal has attracted an inordinate proportion of papers on HIV infection; indeed the HIV load seems to be higher than all other viruses combined, although the imbalance has been counteracted by judiciously chosen reviews and supplements.

The journal has shown an astonishingly short eclipse period between submission and publication; for example, one paper first submitted in August 1996 came out in that month's issue. The publishers should beware of the doubtful ethics of printing to retrospective dates, as authors may be tempted to claim unwarranted precedence for their findings.

Antiviral Therapy is publishing mainly at the clinical-trial end of its spectrum. This focus neatly complements the more molecular Antiviral Chemistry and Chemotherapy and the snappier commentary of International Antiviral News.

We have advanced a long way since the pioneering development of acyclovir to control herpes infections. Our increasing 
understanding of the diverse modes of viral replication may yield a variety of safe, efficacious, antiviral drugs and combination therapies. Later, there will surely be horror stories about epidemics of drug-resistant viruses for the journal to publish.

Robin A. Weiss is at the Institute of Cancer

Research, London SW3 6JB, UK.

\section{Out of Africa}

\section{Tropical Medicine and International Health: A European Journal \\ Coordinating editor D. J. Bradley \\ Blackwell Science. 12/yr. North America

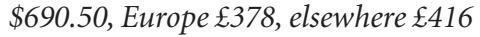 (institutional); North America \$99.50,

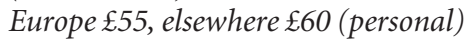

\section{Robert Desowitz}

When Patrick Manson published his Tropical Diseases in 1898, there was no question what constituted a tropical disease: when an Englishman got malaria in the Fens of East Anglia it was an English disease; when an African got malaria it was a tropical disease. With the demise of colonialism, 'tropical medicine' became something of a pejorative.

However, to suggest that the diseases of tropical peoples were really nothing more geographically exclusive than the common cold would not be biologically or epidemiologically correct, and, bereft of the drama of the term, would not be attractive to international funders of health projects in the developing world. Modifiers such as 'international health', 'geographic medicine' and 'travel medicine' have come into fashion, although it is difficult to discern the difference they represent from Manson's Tropical Diseases and the discipline of tropical medicine.

And so to Tropical Medicine and International Health: A European Journal. Actually, this is not a brand new journal but a meld of

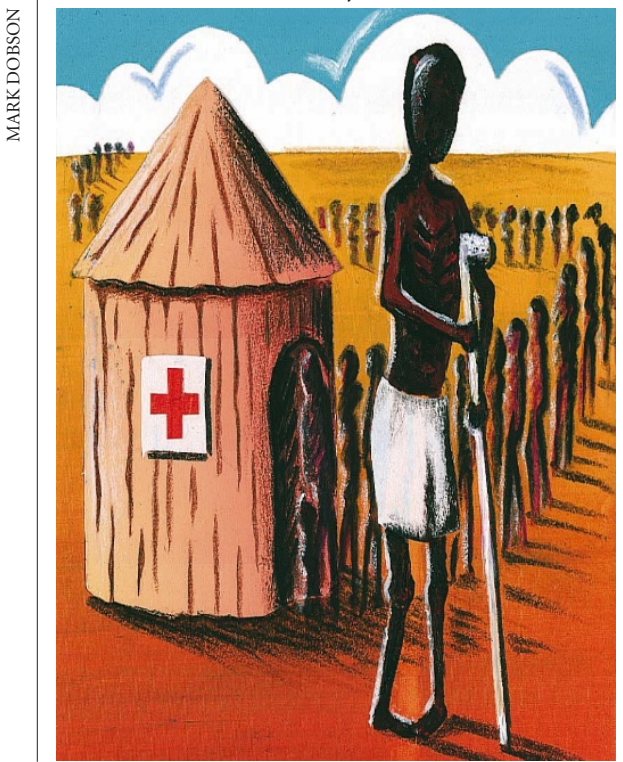

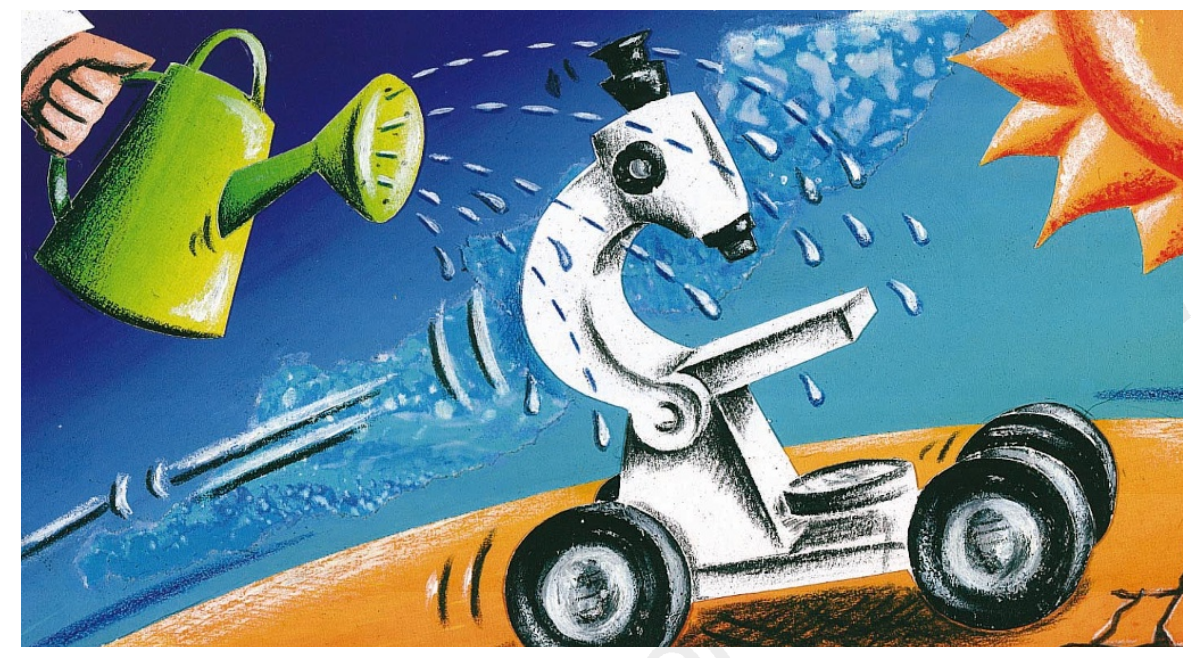

three old journals: the Annales de la Société Belge de Médecine, Journal of Tropical Medicine and Hygiene and Tropical and Geographical Medicine (which itself incorporated Acta Leidensia and Tropical Medicine and Parasitology). Those who wish the discipline of tropical medicine to prosper will have difficulty in deciding whether to rejoice at the founding of a new journal or mourn the loss of three well-established journals.

Each of the old journals had something of a distinct character; they were all good but not great journals. Clinicians, clinical researchers and laboratory scientists would send their good, but not their best, stuff to them. This is in no way to demean those journals, whose contents were very often more meaningful for the understanding, control and management of tropical diseases than the more rarefied papers in the journals considered more exalted in the publication hierarchy.

In reviewing the four issues from December 1996 to March 1997, one gets the impression that the amalgam that is Tropical Medicine and International Health has assumed, gestalt-like, the character of its components. Most of the papers are related to the diseases and health problems of sub-Saharan Africa. The papers are mostly on clinical topics, with or without a laboratory element, and public health studies on sanitation, policy and education.

There are very few (I counted only two) papers that report pure, laboratory-based, experimental research. Each issue begins with an editorial on an important aspect of tropical health, although none shows fire-inthe-belly fierce advocacy.

If I were a member of my institution's or department's library committee, I would certainly recommend subscription to the journal and would personally look forward to reading each new issue. Besides, three for the price of one is a bargain.

Robert Desowitz is at the Department of Epidemiology, School of Public Health, University of North Carolina at Chapel Hill, Chapel Hill, North Carolina 27599, USA.

\section{Development ladder}

\section{Science, Technology and Society: An International Journal Devoted to the Developing World}

Edited by V. V. Krishna and Roland Waast Sage. 2/yr. Rs395, £58, $\$ 88$ (institutional); Rs225, £26, \$38 (personal)

\section{Ziauddin Sardar}

What contribution do science and technology make to the economic development of a developing country? Conventional wisdom suggests that serious expenditure (around three to five per cent of gross national prod$\mathrm{uct}$ ) on research and development (R\&D), particularly in pure sciences, automatically leads to economic development.

But more than five decades of experience now demonstrate that there is no direct connection between the R\&D efforts of a country and its climb up the development ladder. The 'Asian tigers' - Malaysia, Thailand and Indonesia - acquired their 'newly industrialized' status by largely ignoring science and concentrating on manufacturing technology. And countries with highly developed research infrastructures, such as India, Egypt and Brazil, have achieved relatively little in terms of economic development. It turns out that the relationship between science, technology and a developing society is much more complex than the linear model dominant in science policy for so long.

Indeed, the proper study of this complex relationship calls for a new, interdisciplinary field of inquiry. Although the new discipline has to be broadly located in science, technology and society studies, it must have a more specific boundary defined by the cultures, traditions, histories and modern dynamics of developing countries. Science, Technology and Society is designed to map out this territory and to lay the foundations of the new discipline.

In many respects, the journal is similar to Social Studies of Science. It broadly covers the same area from the perspective of the devel- 